International Review of Research in Open and Distributed Learning Volume 22, Number 1

February - 2021

\title{
Book Review: MOOCs and Open Education in the Global South: Challenges, Successes and Opportunities
}

\author{
Editors: Ke Zhang, Curtis J. Bonk, Thomas C. Reeves, and Thomas H. Reynolds (Routledge, 2020, 358 pages) \\ Reviewed by: Dr. Kirk Perris, Commonwealth of Learning
}

MOOCs and Open Education in the Global South: Challenges, Successes, and Opportunities takes readers around the world to gather a deeper understanding of massive open online courses (MOOCs) and open education in an international milieu. With contributions from close to 70 authors and 50 countries, readers will find numerous examples of the ways in which MOOCs differ outside the global North. Content on open education is covered in fewer pages, suggesting more familiarity amongst the authors with the MOOC course type than the open education concept.

The book is organised into seven sections and 28 chapters. Chapters cover six regions of the global South: Africa, Asia, the Caribbean, Latin America, the Middle East, and the Pacific/Oceania, along with a few chapters from the global North. One notable contribution (Chapter 2) places focus on North Korea, one of the most isolated countries on earth. In combination, this diversity demonstrates that MOOCs and open education are otherwise agnostic to political, social, or economic circumstances. A salient feature of the book is the way it summarises its contents. This is first found in the preface, with a series of bullet points and index page references for the 47 countries discussed, and again at the beginning of each section with a descriptive title and a $2-3$ page summary.

Section 1 offers a historical perspective on MOOCs, with a focus on the Korean Peninsula (Chapter 2) and China (Chapter 3). A distinguishing feature of MOOCs in these areas is the governmental role in each context, and both chapters demonstrate how a nationally-planned system of offering MOOCs may yield positive learning outcomes and serve particular purposes. Chapter 2 discusses the popularity of government-sponsored MOOCs in South Korea, where the authors cite that more than $44 \%$ of the population are registered members. The authors suggest that the legitimacy gained from the Korea MOOC system in the South may serve as a diplomatic tool to enhance relations with the North. China has created a large government-supported MOOC ecosystem (Zhang et al., 2019). In Chapter 3, the authors provide a brief overview of MOOCs in China from 2012 and describe MOOC providers, user profiles, and a summary of the research. This analysis will be useful to readers from less mature MOOC ecosystems. Amidst the volume of research discussed, the authors note that more empirical work on pedagogy, attrition, and learner behaviours is needed.

Section 2 explores the design and practices of MOOCs and centres on contextualisation, with input from Canada, Egypt, Fiji, Latin America, Nepal, and the United States. The eight chapters in this section discuss 
the impact of contextual issues on language and learning approaches, resources, and geography. In Chapter 4, which focuses on Egypt, the authors assert that MOOCs are routinely translated from English to another language, yet this is often done without the necessary cultural cues that would enable more "equitable experiences and outcomes" (p. 52). Another issue has been that MOOCs typically rely on a "banking model approach" (p. 49) or a "content-centric focus" (p. 72). Authors in this and other sections advocate for a more learner-centred rather than a didactic approach to MOOC design. A prevailing challenge discussed across the chapters in this section is lack of capacity, which is linked to financial and human resource limitations, another common theme found elsewhere in the book. In addition to pedagogical inputs, Section 2 provides important information on adapting, contextualising, and creating MOOCs. The Climate Change and Pacific Islands MOOC discussed in Chapter 8 is an example of an innovative MOOC that responds to a region beset by the recurrence of natural disasters.

In Section 3, the focus is on the use of open education and MOOCs for professional development, with case studies from Canada, South Africa, Thailand, and Turkey. Adult learners are central to this section, and readers will discover interesting findings on the market appeal and sustainability of MOOCs. An important theme discussed in this section is the centrality of instructors' active engagement and collaboration with learners to the success of MOOCs, reminding us that online learning may not be best characterised as independent learning. Furthermore, success in a MOOC is not necessarily defined as completion; in some cases, participation is, as the authors note in Chapter 14 (Canada).

Section 4 comprises three chapters and discusses the international appeal of MOOCs. Attention is devoted to participant perceptions. In a notable contribution, Chapter 16 reports on the experiences of an international collection of individuals (as learners or instructors) who participated in MOOCs offered by Cornell University in the United States. Beyond learning content, the participants found that MOOCs provided platforms for building community and on-the-ground activities, highlighting tangible social outcomes from the learning experience, reinforcing the point made on participation in the preceding paragraph. Two chapters provide valuable insights on learner perceptions of MOOCs, which are drawn from a collection of emerging world contexts: Chapter 16 on MOOCs used in countries of the Asia-Pacific Economic Cooperation forum, and Chapter 17 on MOOCs used in the Inter-American Development Bank. Both chapters call for a more coordinated effort on the part of governments to strategise nationally and to collaborate regionally to advance the implementation of MOOCs.

Section 5 presents aspects of governmental policies and strategies for open education and MOOCs in four chapters with contributions from Brazil, Malaysia, the Middle East, and the Philippines. Chapter 19 shares findings from a large survey study on the views of institutions on open education across Brazil. A total of 2,660 valid surveys were received from more than 100 public universities with links to the Open University of Brazil (UAB). Survey questions centred on policy and implementation of open education. Findings reveal considerable interest among respondents in advancing open education but little action. The authors highlight that legislation on distance education was not enacted until 1996; and, with the establishment of UAB 10 years later, there is likely much room for growth in open education in Brazil. In Chapter 20, the author reflects on the Malaysian government's stipulation that by 2015 all public universities offer $15 \%$ of courses as MOOCs and $30 \%$ by 2020, with an emphasis on pedagogical training for online learning and a view to sustainability. The author concludes that much work remains. 
Another governmental open education initiative emanates from the Philippines (Chapter 21). The Philippine Commission for Higher Education has been supporting the OERs for Development Framework (OERs4D), and the authors describe a sequence of events that has led to wider implementation of MOOCs across the archipelago. MOOCs, as a product of the OERs4D, embrace the universal design for learning framework and other accessibility considerations (e.g., mobile-enabled platforms) to enhance uptake. In the final chapter of this section (Chapter 22), the authors discuss government-sanctioned MOOC interventions in several states in the Middle East, including Egypt, Jordan, Lebanon, Saudi Arabia, and others. The authors view MOOCs as filling an unmet demand for learning, citing examples of the large populations in the region and the appeal of MOOCs to refugees, individuals in conflict zones, and female learners. The authors lament, however, that there is a dearth of MOOCs in Arabic. A search conducted online revealed that the two dominant Arabic MOOC sites, Rwaq and Edraak, list approximately 650 MOOCs for adult and higher education. The contextualisation of MOOCs, however, should focus on more than language. There are cultural (i.e., gender) and geopolitical (i.e., conflict) factors that can serve to make MOOCs a unique learning experience.

Section 6 focuses on the innovations and scalability of MOOCs. Chapter 23 focuses on the learning opportunities of the World Bank's Open Learning Campus (e.g., courses, repositories, and reports, among others), which have reached more than 4 million individuals. Much of the materials focus on sustainable development goals. While enrolment benefits from the vast network of the World Bank, the singular focus on a topical area (e.g., climate change, machine learning) demonstrates the potential for scale. Chapter 24, focuses on fostering a culture of open education practices (OEPs) through capacity building in adopting open educational resources (OERs). The chapter centres on a study of 26 individuals from six countries located in Sub-Saharan Africa. While some progress was made in the uptake of OEPs, the authors believe that for OEPs to be more fully realised, a wholesale institutional approach is needed.

Chapter 25 focusses on the scalability of MOOCs through an innovative, low-bandwidth solution. A team from the Commonwealth of Learning and the Indian Institute of Technology, Kanpur, designed a learning management system called mooKIT. From 2015-2018, MOOCs offered on mooKIT attracted learners from 94 countries and an aggregate enrolment of more than 44,00o learners. Close to $25 \%$ of the learners that enrolled received a certificate of completion, at a per certificate cost of US $\$ 11$. This case demonstrates that a low-bandwidth solution may enable the enrolment of many more learners than would otherwise be possible. Chapter 26 presents another low-cost solution to access education through MOOCs for a collection of Kenyan learners with limited technological skills. The study revealed that learner supports implemented during the onboarding phase to learning online may have been integral to increasing completion rates in the MOOC.

The seventh and final section of the book looks to the future of MOOCs and open education. In Chapter 27, the authors predict that artificial intelligence (AI) will be increasingly mainstreamed in education, opening doors for intelligent MOOCs that will enable greater focus on personalised education. The 28th and concluding chapter is authored by the four editors, who offer 10 predictions on MOOCs and open education. To mention a few, the authors predict that in 15 to 20 years,

- $\quad$ MOOCs will primarily target working adults who are focused on up/re-skilling. 
- AI will update MOOCs and OERs, with the role of humans limited to quality assurance.

- MOOC design will become more learner-centred and enabled through authentic and interactive learning experiences.

The editors conclude with an outlook that is both ominous and optimistic. The world of work is changing, perhaps more rapidly than the average person realises, with the onset of AI and automation. Whether in Silicon Valley or rural Sudan, technology is changing society and making employment increasingly specialised. To address this change, the editors advocate for a greater uptake of "a massively open distributed education ecology of MOOCs and OER" (p. 347).

Throughout the book, there is a wealth of information for individuals seeking a deeper understanding of how MOOCs and open education are being adopted around the world. The global South, upon which the book is focused, presents issues that are largely known in the field of open education and MOOCs: uneven Internet connectivity, lack of financial resources, need for capacity building, and reliance on outdated design and pedagogical approaches. These issues notwithstanding, there are some important findings in the different chapters relative to innovations, scalability, and cross-country partnerships. Some examples are language considerations, courses that have only regional appeal, use of low-bandwidth solutions, and development of transnational partnerships.

The most likely outcome of the editors' predictions is that MOOCs will continue to appeal to working adults given the ongoing need to acquire or refine their skills. Connectivity issues around the world will persist; and MOOCs are not overly helpful in addressing this challenge given their great reliance on videos, which require large amounts of bandwidth and data. Indeed, the mooKIT learning management system (Chapter 25) presents a low-bandwidth alternative; but mainstreaming other aspects of open education should garner greater attention. Increased uptake of OER needs sectoral if not ministerial leadership. OER has proven to be cost effective in reducing textbook costs (Caldwell, 2020; Wiley et al., 2012), particularly as open textbooks. Yet, political will, comprehensive capacity building, and financial resources are key to moving such initiatives forward. Any interventions must also be located in identifying and understanding a given problem to which open education and MOOC interventions are the solution. One-off projects, in the absence of sound strategic considerations, offer little to address the problem of access to quality learning. Instead, any intervention must be couched in a view to sustainability and, ultimately, impact for learners. 


\section{References}

Caldwell, J. (2020, March 23). Ongoing adoption: Estimating, calculating, and tracking. BCCampus. Retrieved from https://bccampus.ca/2020/03/23/ongoing-adoption-estimating-calculating-andtracking/

Wiley, D., Hilton III, J. L., Ellington, S., \& Hall, T. (2012). A preliminary examination of the cost savings and learning impacts of using open textbooks in middle and high school science classes. The International Review of Research in Open and Distributed Learning, 13(3), 262-276. https://doi.org/10.19173/irrodl.v13i3.1153

Zhang, J., Sziegat, H., Perris, K., \& Zhou, C. (2019). More than access: MOOCs and changes in Chinese higher education. Learning, Media, and Technology, 44(2), 108-123.

https://doi.org/10.1080/17439884.2019.1602541

\section{Athabasca}

University

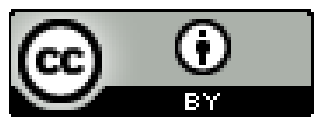

